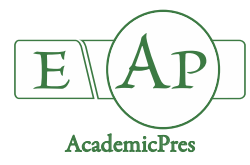

\title{
Optimization of the Solid-Liquid Extraction Process of Phenolic Compounds from Mulberry Fruit
}

\author{
Emilija KOSTIĆ ${ }^{*}$, Biljana ARSIĆ ${ }^{2}$, Milan MITIĆ2, \\ Danica DIMITRIJEVIĆ ${ }^{2}$, Emilija PECEV MARINKOVIC ${ }^{2}$ \\ ${ }^{1}$ University of Niš, Faculty of Medicine, Department of Pharmacy, Serbia; emilija293@gmail.com \\ ${ }^{2}$ University of Niš, Faculty of Sciences and Mathematics, Department of Chemistry, Niš, \\ Serbia;ba432@ymail.com,milanmitic83@yahoo.com,danicadimitrijevic7@gmail.com,epecev@yahoo.com
}

\begin{abstract}
The study was designed to examine the influence of solvent concentration (ethanol/water $20-80 \%$ by volume), extraction time (15-240 min) and extraction technique on the extraction yield of phenolic compounds, flavonoids and antioxidant activity from Morus nigra L., Morus rubra L. and Morus alba L. fruits. The optimum conditions for the extraction of total phenols, flavonoids and monomeric anthocyanins by the maceration and ultrasonic extraction processes were: 213.6 min with 80\% ethanol, and $182.1 \mathrm{~min}$ and $71.2 \%$ ethanol, respectively (black mulberry), and 216.5 min with $78.3 \%$ ethanol and 198.7 min and $70.6 \%$ ethanol, respectively (red mulberry). In case of white mulberry for the extraction of total phenols and flavonoids optimum extraction conditions (maceration and ultrasonic) were $232.7 \mathrm{~min}$ and $80 \%$ ethanol, and $187.2 \mathrm{~min}$ and $68.7 \%$ ethanol, respectively (white mulberry). Obviously, ultrasonic extraction was less time consuming, and it requires for all performed extractions solvent with less percentage of ethanol.
\end{abstract}

Keywords: anthocyanins; flavonoids; maceration; phenolics; response surface methodology; ultrasonic extraction

\section{Introduction}

Genus Morus is widespread in Asia, Europe, North and South America and Africa. Mulberry is growing in the temperate and sub-tropical regions of the northern hemisphere (Özgen et al., 2009). Black and white mulberry are quite widespread in the area of Serbia (Kostić et al., 2013). The black and red mulberries are found to be especially rich in anthocyanins, flavonoids and phenol compounds (Özgen et al., 2009). The total content of these compounds depends on the geographic location, soil on which the mulberry tree grows, type of extraction, length of extraction, type of solvent. Mulberry gives the uniquely delicious fruit of sour and refreshing taste. Therefore, it is not surprising that it has been used as a folk remedy to treat oral and dental diseases, diabetes, hypertension, arthritis and anemia (Mahesh et al., 2017). The bright black mulberry fruits, which have a very pleasant taste when eaten fresh, are also used in jams, juices, liquors, natural dyes as well as in the cosmetic industry (Gerasopoulos and Stavroulakis, 1997).

The chemical compositions of white, red and black mulberries were determined. It was found that the highest total phenolic and flavonoid yields were observed in black mulberry (Ercisli and Orhan, 2007). To the best of our knowledge, there are few reports on the optimization of mulberry leaf extraction (Teng and Lee 2013; Tchabo et al., 2015).

There are no available literature data on the optimization of the extraction of mulberry fruit by different ethanol-water solution, nor of the extraction efficiency and the impact of various extraction techniques on the yield and the phenolic composition. The mulberry and its extracts can be used as a good source of natural plant pigment and antioxidant agents. This study will be of considerable interest to the commercial growers of mulberry trees or pharmaceutical industry for potential mulberry supplement production.

The aim of the study is the determination of the effects of the several parameters (extraction time, solvent concentration, extraction method) on the yield of phenolic compounds, flavonoids, and anthocyanins from black, red and white mulberry, and obtaining of optimum conditions computationally using a response surface model. In earlier studies of the extraction kinetics using different techniques, it was found that higher yields are achieved using circulation techniques comparing to the maceration. The operating conditions have an impact on the extraction yield and the kinetics of extraction (Stanojevic et al., 2007; Grujic et al., 2012). 
630

\section{Materials and Methods}

The plant material-fruits of Morus nigra L., Morus rubra L. and Morus alba L. were collected in South-East Serbia in early July 2017.

\section{Apparatus and reagents}

An Agilent 8453 UV-vis spectrophotometer (USA) was used for the absorbance measurements and spectra recording, using an optical or quartz cuvettes of $1 \mathrm{~cm}$ optical path. The $\mathrm{pH}$ measurements were made with Hanna Instruments $\mathrm{pH}$-meter (USA) equipped with the glass electrode.

The Folin-Ciocalteu phenol reagent and sodium carbonate were purchased from Merck Chemical Suppliers (Darmstadt, Germany). Sodium chlorate buffer ( $\mathrm{pH} 1.0$ ) and acetate buffer ( $\mathrm{pH} 4.5)$ were purchased from the same producer. The other used chemicals including solvents were of analytical grade.

\section{Maceration}

Triturated and homogenized fresh mulberry fruit (10 g) was soaked into the mixture of the previously prepared solvent: ethanol-water- $\mathrm{HCl}(20: 79: 1 v / v / v)$, ethanol-water$\mathrm{HCl}(50: 39: 1 \quad v / v / v)$ and ethanol-water-HCl (80:19:1 $v / v / v)$ at a ratio of 1:10 w/v. Maceration with a solvent system was performed at $15,127.5$ or $240 \mathrm{~min}$ at $25^{\circ} \mathrm{C}$. The suspension was then filtered through a Buchner funnel and Whatman No.1 filter paper. The extracts were stored in the refrigerator and in the dark to their further use for the determination of phenolic compounds (Dean, 2009).

\section{Ultrasonic extraction}

Milled plant material (10 g) was extracted with the previously mentioned solvent systems in the thermostatic ultrasonic bath (Sonic, Niš, Serbia) with the nominal power: $3 \times 50 \mathrm{~W}$; dimensions of bathrooms: $30 \times 15 \times 20 \mathrm{~cm}$, and at a frequency of $40 \mathrm{kHz}$. The kinetics of the extraction of phenolic compounds were collected at the indicated time intervals (15-240 minutes). The extracts were separated from the plant material on Buchner's funnel with a weak vacuum and further treated according to the procedure for the determination of total phenols (Vinatoru, 2015).

\section{Determination of total phenolics}

Total phenol contents of the extracts were found by the modified Folin-Ciocalteu method. An aliquot of the extracts $(1 \mathrm{~mL})$ was mixed with $0.5 \mathrm{~mL}$ Folin-Ciocalteu reagent and $2 \mathrm{~mL}$ of sodium carbonate (20\%). The absorbance was recorded after $10 \mathrm{~min}$ of the incubation at room temperature at $760 \mathrm{~nm}$. The total phenolic content was expressed as $\mathrm{mg} / 100 \mathrm{~g}$ gallic acid equivalent (GAE). The result of each assay was obtained from 3 parallel determinations (Singleton and Rossi, 1965).

\section{Determination of total flavonoid content}

Total flavonoid content was determined using a spectrophotometric method based on the formation of flavonoid complex with aluminum. Total flavonoid content was calculated as catechin $(\mathrm{mg} \mathrm{CE} / 100 \mathrm{~g})$ using the equation based on the calibration curve (Stojanovic et al., 2016).

\section{Determination of the total monomeric anthocyanins}

The total monomeric anthocyanin content in the plant extracts was determined using the $\mathrm{pH}$-differential method previously described. The result, taken as the monomeric anthocyanin pigment (MAP), was shown as mg of cyanidin3-O-glucoside/L (Giusti and Wrolstad, 2001).

\section{Response surface methodology and optimum conditions for the extraction}

Response surface design and the finding of the optimum conditions for the optimization of maceration and ultrasonic extractions were achieved using the software JMP 14.0.1 (SAS Institute Inc., Cary, USA) (Mietlowski, 2008). Two factors were selected: time $(15 \mathrm{~min}, 127.5 \mathrm{~min}$, and $240 \mathrm{~min})$ and $\%$ ethanol (20\%, 50\%, and $80 \%)$, and three responses: total phenols, flavonoids and monomeric anthocyanins in case of black and red mulberries, and two responses (total phenols and flavonoids) for white mulberry, and the Central Composite Design with 2 central points. The script for the model was run, and the results were displayed with all statistical data. The optimum conditions regarding time and the solvent system were found using the option of Prediction profiler and the selection of Maximize Desirability. The average value of the optimum time and the solvent system was found from three measurements.

\section{Results and Discussion}

In Table 1 it is shown the dependence of the contents of total phenols in ethanol-aqueous extracts of mulberry fruit on time with different concentrations of ethanol $(20,50$ and $80 \%$ ) of maceration process and ultrasonic extraction. The process lasted 15, 127.5 and $240 \mathrm{~min}$. Total phenol content was shown as mg gallic acid equivalents (GAE) per $100 \mathrm{~g}$ of fruit.

The content of total phenolics in the tested extracts of black mulberry ranges for maceration and ultrasonic extractions from 60.04 to $150.13 \mathrm{mg}$ and 69.11 to 142.18 $\mathrm{GAE} / 100 \mathrm{~g}$ fresh fruit, respectively.

Table 1. Average of total phenolic content in different extracts of mulberry fruits for five repetitions (mg GAE/100 $\mathrm{g}$ f.w.)

\begin{tabular}{|c|c|c|c|c|c|c|c|c|c|c|c|c|c|c|c|c|c|c|}
\hline \multirow{3}{*}{$\begin{array}{c}\mathrm{T} \\
\text { Ethanol }\end{array}$} & \multicolumn{6}{|c|}{$15 \mathrm{~min}$} & \multicolumn{6}{|c|}{$127.5 \mathrm{~min}$} & \multicolumn{6}{|c|}{$240 \mathrm{~min}$} \\
\hline & \multicolumn{2}{|c|}{ Black } & \multicolumn{2}{|c|}{ Red } & \multicolumn{2}{|c|}{ White } & \multicolumn{2}{|c|}{ Black } & \multicolumn{2}{|c|}{ Red } & \multicolumn{2}{|c|}{ White } & \multicolumn{2}{|c|}{ Black } & \multicolumn{2}{|c|}{ Red } & \multicolumn{2}{|c|}{ White } \\
\hline & mac. & u.s. & mac. & u.s. & mac. & u.s. & mac. & u.s. & mac. & u.s. & mac. & u.s. & mac. & u.s. & mac. & u.s. & mac. & u.s. \\
\hline $20 \%$ & $\begin{array}{l}60 . \\
04\end{array}$ & $\begin{array}{c}69 . \\
11\end{array}$ & 50.05 & 62.20 & 45.10 & 55.06 & 100.12 & 101.02 & 92.04 & 92.08 & 88.02 & 86.05 & 118.00 & 100.11 & 112.14 & 88.15 & 107.12 & 81.04 \\
\hline $50 \%$ & $\begin{array}{c}77 . \\
12\end{array}$ & $\begin{array}{l}93 . \\
04\end{array}$ & 70.11 & 84.12 & 63.21 & 77.14 & 120.13 & 120.06 & 105.07 & 110.11 & 99.06 & 98.13 & 128.12 & 120.15 & 120.17 & 112.13 & 113.09 & 103.09 \\
\hline $80 \%$ & $\begin{array}{c}90 . \\
07\end{array}$ & $\begin{array}{c}110 . \\
10\end{array}$ & 80.09 & 100.03 & 74.14 & 92.09 & 137.08 & 140.15 & 122.13 & 125.05 & 111.04 & 101.75 & 150.13 & 142.18 & 138.18 & 129.07 & 130.05 & 121.07 \\
\hline
\end{tabular}


In the period of the rapid extraction, washing, and dissolving of the extractive matter from the surface of the destroyed cells of plant material proceeded with more than $90 \%$ of total phenols. It shows that the fragmentation of the plant material used for the tests is relatively high with a high degree of the destruction of cells.

The extraction process with ultrasonic mixing is much more efficient than extraction by maceration. The most likely mechanism of action of ultrasonic extraction is intensifying mass transfer and easier penetration of the solvent into the cells of the plant material. In the classical maceration normal mechanism of diffusion through the cell walls is occurred, and therefore this process requires a much longer extraction time (Milenovic et al., 2002).

In Table 2 it is shown the dependence of the contents of flavonoids in the extracts on time with different contents of ethanol obtained by maceration and ultrasonic extraction. The flavonoid content is expressed as $\mathrm{mg}$ catechin equivalents (CE) per $100 \mathrm{~g}$ of fruit.

The flavonoid content of the extract of black mulberry obtained by maceration and ultrasonic extraction is ranged from 60.02 to 82.08 and from 53.13 to $108.16 \mathrm{mg}$ $\mathrm{CE} / 100 \mathrm{~g}$, respectively. Red and white mulberry have less content of flavonoids in all investigated extracts. After the extraction of $120 \mathrm{~min}$ by the maceration, an increase in the yield of flavonoids to $240 \mathrm{~min}$ is slower. The application of the ultrasonic extraction increases the yield of flavonoids in the tested extracts at the same conditions.

In Table 3 it is shown the dependence of the content of the monomeric anthocyanins with maceration time and ultrasonic extraction for different compositions of the mixture. The content of anthocyanin is expressed as $\mathrm{mg}$ of cyanidin-3-O-glucoside per $100 \mathrm{~g}$ of the fruit.

Anthocyanin content of the extracts obtained by the process of maceration ranges from 52.03 to 137.06 for maceration and from 64.08 to $137.06 \mathrm{mg}$ Cy-3-O-glu/100 g for ultrasonic extraction for black mulberry.

The fragmentation of the plant material used for testing is relatively high. A higher degree of the destruction of cells increases the surface area from which in a rapid period extractive matter was washed down quickly and thus provides a high level of the extraction in this period.

In a period of a rapid extraction (120 min), by maceration, it was extracted $78.60 \%$ of total extractive matter, $86.89 \%$ of total phenolic compounds, $85.22 \%$ of flavonoids and $75.51 \%$ of anthocyanins. The period of rapid extraction by ultrasonic extraction was 120 min for dry residue and flavonoids ( 85.33 and $86.23 \%$, respectively) and $60 \mathrm{~min}$ for total phenolic (81.95\%) and anthocyanins (86.07\%).

The computational modeling-response surface design and subsequent optimization give more easily optimized conditions for both maceration, and ultrasonic extraction (Fig. 1).

The optimum conditions for the extraction of total phenols, flavonoids and monomeric anthocyanins by the maceration process were $213.6 \mathrm{~min}$ with $80 \%$ ethanol (black mulberry), and 216.5 min with $78.3 \%$ ethanol (red mulberry), and $232.7 \mathrm{~min}$ and $80 \%$ ethanol (white mulberry) for the extraction of total phenols and flavonoids. In case of ultrasound extraction, the extraction of total phenols, flavonoids, and total anthocyanins was the most effective with $182.1 \mathrm{~min}$ and $71.2 \%$ ethanol (black mulberry), and $198.7 \mathrm{~min}$ and $70.6 \%$ ethanol (red mulberry), and the extraction of total phenols and flavonoids with 187.2 min and $68.7 \%$ ethanol for white mulberry.

Optimizations of ultrasonic-assisted extractions were performed before for the black mulberry (Zou et al., 2011; Espada-Bellido et al., 2017), but different factors were chosen comparing to our analysis.

Solid-liquid extractions were optimized considering the antioxidants and saccharides from black mulberry fruit (Radojkovic et al., 2013; Fang et al., 2014). Mulberry leaves were also the subject of the investigation of the optimal conditions for the extraction (Radojkovic et al., 2012a, b; Tchabo et al., 2018). The response surface methodology was used not only for ultrasonic extractions but also for microwave-assisted extractions of mulberries (Teng and Lee, 2013; Zou et al., 2012).

Table 2. Average of flavonoid content in different extracts of mulberry fruits for five repetitions ( $\mathrm{mg} \mathrm{CE} / 100 \mathrm{~g}$ f.w.)

\begin{tabular}{|c|c|c|c|c|c|c|c|c|c|c|c|c|c|c|c|c|c|c|}
\hline \multirow{3}{*}{$\begin{array}{c}\mathrm{T} \\
\text { Mulberry } \\
\text { Ethanol }\end{array}$} & \multicolumn{6}{|c|}{$15 \mathrm{~min}$} & \multicolumn{6}{|c|}{$127.5 \mathrm{~min}$} & \multicolumn{6}{|c|}{$240 \mathrm{~min}$} \\
\hline & \multicolumn{2}{|c|}{ Black } & \multicolumn{2}{|c|}{ Red } & \multicolumn{2}{|c|}{ White } & \multicolumn{2}{|c|}{ Black } & \multicolumn{2}{|c|}{ Red } & \multicolumn{2}{|c|}{ White } & \multicolumn{2}{|c|}{ Black } & \multicolumn{2}{|c|}{ Red } & \multicolumn{2}{|c|}{ White } \\
\hline & mac. & u.s. & mac. & u.s. & mac. & u.s. & mac. & u.s. & mac. & u.s. & mac. & u.s. & mac. & u.s. & mac. & u.s. & $\mathrm{mac}$ & u.s \\
\hline $20 \%$ & 60.02 & 53.13 & 52.14 & 50.10 & 45.06 & 44.16 & 71.13 & 84.00 & 62.03 & 77.08 & 56.16 & 71.07 & 72.14 & 86.16 & 63.03 & 78.12 & $\begin{array}{l}58 . \\
02\end{array}$ & $\begin{array}{l}73 . \\
06\end{array}$ \\
\hline $50 \%$ & 67.12 & 70.08 & 56.09 & 66.08 & 50.04 & 61.12 & 76.06 & $\begin{array}{c}107 . \\
11\end{array}$ & 71.05 & $\begin{array}{c}102 . \\
15\end{array}$ & 64.13 & 98.09 & 78.19 & $\begin{array}{c}108 \\
16\end{array}$ & 71.06 & $\begin{array}{c}102 . \\
06\end{array}$ & $\begin{array}{l}63 . \\
06\end{array}$ & $\begin{array}{l}96 . \\
08\end{array}$ \\
\hline $80 \%$ & 72.05 & 75.11 & 60.03 & 70.01 & 56.10 & 63.06 & 80.04 & 96.15 & 76.10 & 89.05 & 59.04 & 83.12 & 82.08 & 96.12 & 75.10 & 89.09 & $\begin{array}{l}66 . \\
09\end{array}$ & $\begin{array}{r}82 \\
10\end{array}$ \\
\hline
\end{tabular}

Table 3. Average of total anthocyanin content in different extracts of mulberry fruits for five repetitions ( $\mathrm{mg}$ cyanidin-3-O-glucoside / $100 \mathrm{~g}$ f.w.)

\begin{tabular}{|c|c|c|c|c|c|c|c|c|c|c|c|c|c|c|c|c|c|c|}
\hline \multirow{3}{*}{$\begin{array}{c}\mathrm{T} \\
\text { Ethanol }\end{array}$} & \multicolumn{6}{|c|}{$15 \mathrm{~min}$} & \multicolumn{6}{|c|}{$127.5 \mathrm{~min}$} & \multicolumn{6}{|c|}{$240 \mathrm{~min}$} \\
\hline & \multicolumn{2}{|c|}{ Black } & \multicolumn{2}{|c|}{ Red } & \multicolumn{2}{|c|}{ White } & \multicolumn{2}{|c|}{ Black } & \multicolumn{2}{|c|}{ Red } & \multicolumn{2}{|c|}{ White } & \multicolumn{2}{|c|}{ Black } & \multicolumn{2}{|c|}{ Red } & \multicolumn{2}{|c|}{ White } \\
\hline & mac. & u.s. & mac. & u.s. & mac. & u.s. & mac. & u.s. & mac. & u.s. & mac. & u.s. & mac. & u.s. & mac. & u.s. & $\mathrm{mac}$ & u.s \\
\hline $20 \%$ & 52.03 & 64.08 & 41.06 & 52.12 & 0.01 & 0.01 & 96.02 & 92.09 & 81.05 & 74.12 & 0.01 & 0.01 & $\begin{array}{c}110 . \\
01\end{array}$ & 94.11 & $\begin{array}{c}105 . \\
02\end{array}$ & 75.04 & 0.01 & $\begin{array}{c}0 . \\
02\end{array}$ \\
\hline $50 \%$ & 68.09 & 86.05 & 56.03 & 65.15 & 0.02 & 0.01 & $\begin{array}{c}125 \\
12\end{array}$ & $\begin{array}{c}110 . \\
10\end{array}$ & $\begin{array}{c}110 . \\
07\end{array}$ & 90.06 & 0.01 & 0.02 & $\begin{array}{c}137 . \\
06\end{array}$ & $\begin{array}{c}118 . \\
05\end{array}$ & $\begin{array}{c}126 . \\
12\end{array}$ & $\begin{array}{c}101 . \\
08\end{array}$ & 0.01 & $\begin{array}{l}0 . \\
01\end{array}$ \\
\hline $80 \%$ & 72.12 & 86.16 & 61.11 & 66.18 & 0.01 & 0.02 & $\begin{array}{c}118 . \\
13\end{array}$ & $\begin{array}{c}110 . \\
13\end{array}$ & $\begin{array}{c}102 . \\
01\end{array}$ & 88.13 & 0.01 & 0.01 & $\begin{array}{c}123 . \\
10\end{array}$ & $\begin{array}{c}110 . \\
03\end{array}$ & $\begin{array}{c}108 . \\
18\end{array}$ & $\begin{array}{c}100 \\
10\end{array}$ & 0.01 & $\begin{array}{c}0 . \\
02\end{array}$ \\
\hline
\end{tabular}



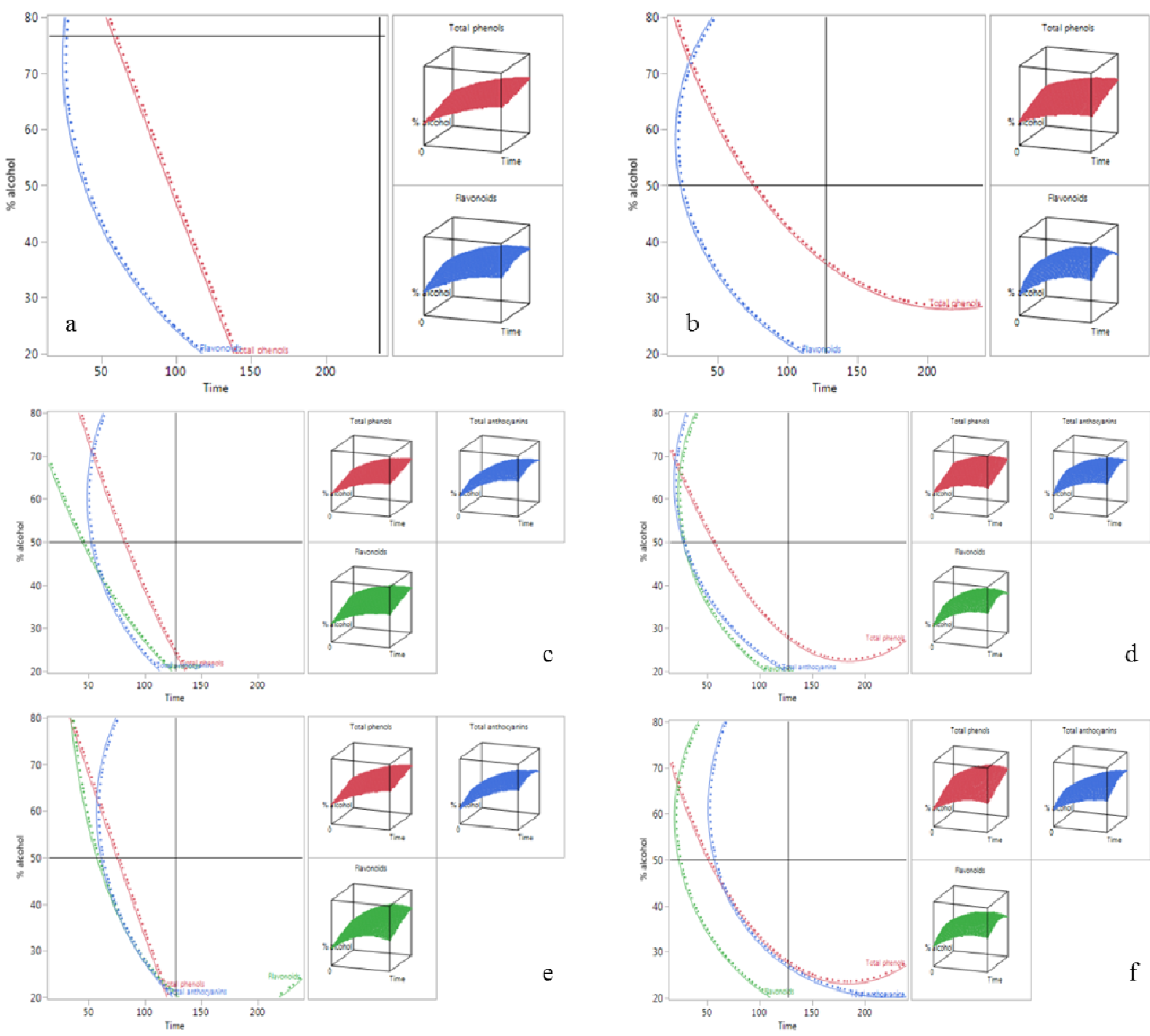

Fig. 1. Contour profilers of the extraction processes: a) white mulberry, maceration; b) white mulberry, ultrasound; c) black mulberry, maceration; d) black mulberry, ultrasound; e) red mulberry, maceration; f) red mulberry, ultrasound

\section{Conclusions}

The differences in the content of total phenols, flavonoids and total anthocyanins for the extractions are the results of different polarities of the applied solvent systems, differences in the Morus species, extraction technique and time. The computational modeling-response surface design and subsequent optimization give more easily optimized conditions for both maceration and ultrasonic extraction. The obtained results show that the ultrasonic extraction was less time consuming and requires a solvent system with less percentage of ethanol. The results indicate a high content of phenolic compounds, flavonoids, and anthocyanins of black mulberry located in Southeast Serbia, which confirm its nutritional and pharmacological potential.

\section{Acknowledgements}

Financial support for this work was obtained by the Serbian Ministry of Education, Science and Technological Development, Project No. ON 172047 and 174007.

\section{References}

Dean JR (2009). Extraction techniques in analytical sciences (Vol. 34).John Wiley \& Sons, Ltd.

ErcisliS, Orhan E (2007). Chemical composition of white (Morus alba), red (Morus rubra) and black (Morus nigra) mulberry fruits. Food Chemistry 103(4):1380-1384. 
Espada-Bellido E, Ferreiro-González M, Carrera C, Palma M, Barroso CG, Barbero GF (2017). Optimization of the ultrasound-assisted extraction of anthocyanins and total phenolic compounds in mulberry (Morus nigra) pulp. Food Chemistry 219:23-32.

Fang M, Yan W, Chen K, Ying Z, Han X (2014). Optimization of ultrasound-assisted extraction of polysaccharides from mulberry leaves by response surface methodology. Asian Journal of Chemistry 26(21):72147220.

Gerasopoulos D, Stavroulakis G (1997). Quality characteristics of four mulberry (Morus sp.) cultivars in the area of Chania, Greece. Journal of the Science of Food and Agriculture 73(2):261-264.

Giusti MM, Wrolstad RE (2001). Anthocyanins. Characterization and measurement of anthocyanins by UV-visible spectroscopy. In: Wrolstad RE (Ed). Current Protocols in Food Analytical Chemistry, John Wiley \&Sons: New York, 2001; unitF1.2.1-1.

Grujic N, Lepojevic Z, Srdjenovic B, Vladic J, Sudji J (2012). Effects of different extraction methods and conditions on the phenolic composition of mate tea extracts. Molecules 17(3):2518-2528.

Kostić DA, Dimitrijević DS, Mitić SS, Mitić MN, Stojanović GS, Živanović AV (2013). A survey on macro- and micro-elements, phenolic compounds, biological activity and use of Morus spp. (Moraceae). Fruits 68(4):333-347.

Mahesh DS, Vidhathri BS, Vidyashree DN, Narayanaswamy TK, Subbarayappa CT, Muthuraju R (2017). Biochemical composition and pharmacological properties of mulberry (Morus spp.) - a review. International Journal of Current Microbiology and Applied Sciences 6(7):2207-2217.

Mietlowski W (2008). A review of: pharmaceutical statistics using SAS: a practical guide. In: Dmitrienko A, Chuang-Stein C, D'Agostino RB (Eds).Journal of Biopharmaceutical Statistics 18(3):590-594.

Milenovic D, Veljkovic V, Todorovic B, Stankovic M (2002). Extraction of resinoids from St. John's wort (Hypericum perforatum L.). I. Efficiency and optimization of extraction. Chemical Industry 56(2):5459.

Özgen M, Serçe S, Kaya C (2009). Phytochemical and antioxidant properties of anthocyanin-rich Morus nigra and Morus rubra fruits. ScientiaHorticulturae 119(3):275-279.

Radojkovic M, Zekovic Z, Jokic S, Vidovic S (2012a). Determination of optimal extraction parameters of mulberry leaves using response surface methodology (RSM). Romanian Biotechnological Letters 17(3):72977310.

Radojkovic M, Zekovic Z, Jokic S, Vidovic S, Lepojevic Z, Milosevic S (2012b). Optimization of solid-liquid extraction of antioxidants from black mulberry leaves by response surface methodology. Food Technology and Biotechnology 50(2):167-176.
Radojkovic M, Zekovic Z, Sudar R, Jokic S, Cvetanovic A (2013). Optimization of solid-liquid extraction of antioxidants and saccharides from black mulberry fruit by response surface methodology. Journal of Food and Nutrition Research 52(3):146-155.

Singleton VL, Rossi JA (1965). Colorimetry of total phenolics with phosphomolybdic phospho-tungstic acid reagents. American Journal of Enology and Viticulture 16(3):144-158.

Stanojevic LJ, Stankovic M, Nikolic LJ, Nikolic V (2007) The influence of the operation conditions and the extraction techniques on the yield, kinetics and the composition of ethanol extracts of Hieracium pilosella $\mathrm{L}$. Chemical Industry and Chemical Engineering Quarterly 13(4):199204.

Stojanovic B, MiticS, Stojanovic G, Mitic M, KosticD, Paunovic D, Arsic $B$ (2016). Phenolic profile and antioxidant activity of pulp and peel from peach and nectarine fruits. Notulae Botanicae Horti Agrobotanici ClujNapoca 44(1):175-182.

Tchabo W, Ma Y, Engmann FN, Zhang H (2015). Ultrasound-assisted enzymatic extraction (UAEE) of phytochemical compounds from mulberry (Morus nigra) must and optimization study using response surface methodology. Industrial Crops Product 63:214225.

Tchabo W, Ma Y, Kwaw E, Xiao L, Wu M, Apaliya MT (2018). Impact of extraction parameters and their optimization on the nutraceuticals and antioxidant properties of aqueous extract mulberry leaf. Inernational Journal of FoodProperties 21(1):717-732.

Teng H, Lee WY (2013). Optimization of microwave-assisted extraction of polyphenols from mulberry fruits (Morus alba L.) using response surface methodology. Journal of the Korean Society for Applied Biological Chemistry 56(3):317-324.

Vinatoru M (2015). Ultrasonically assisted extraction (UAE) of natural products some guidelines for good practice and reporting. Ultrasonics Sonochemistry 25:9495.

Zou T, Wang D, Guo H, Zhu Y, Luo X, Liu F, Ling W (2012). Optimization of microwave-assisted extraction of anthocyanins from mulberry and identification of anthocyanins in extract using HPLCESI-MS.Journal of Food Science 77(1):C46-C50.

Zou T-B, Wang M, Gan R-Y, Ling W-H (2011). Optimization of ultrasound-assisted extraction of anthocyanins from mulberry, using response surface methodology. International Journal of Molecular Sciences 12(5):3006-3017. 